\section{Verteporfin therapy in occult with no classic CNV due to AMD: results of the Photodynamic Therapy in Occult- Only Lesions study}

G Soubrane', SP Harding 2 , S Wolf ${ }^{3}$ and

A Weichselberger ${ }^{4}$, Photodynamic Therapy in

Occult-Only Lesions (POOL) Study Group

\begin{abstract}
Purpose To provide further information on verteporfin photodynamic therapy in occult with no classic choroidal neovascularization (CNV) secondary to age-related macular degeneration (AMD).

Methods Verteporfin therapy was administered at baseline and then at months 3, 6, and 9, if fluorescein leakage from CNV was evident on angiography.
\end{abstract}

Results Of 202 patients enrolled, 184 completed 12 months. Each patient was treated in one eye only. All study eyes received verteporfin therapy at baseline, with a progressive decrease in the number treated at subsequent visits (mean 2.5 treatments during 12 months). The mean change in visual acuity letter score from baseline to month $\mathbf{1 2}$ was

-11.9. At month 12, 164 eyes $(82.4 \%)$ had lost $<30$ letters of visual acuity, 123 eyes $(61.8 \%)$ had lost $<15$ letters, 78 eyes $(39.2 \%)$ had lost $<5$ letters, 31 (15.6\%) had > 5-letter increase, and $7(3.5 \%)$ had $>15$-letter improvement. The percentage of eyes with fluorescein leakage from CNV decreased from $75.5 \%$ at month 3 to 25.1\% at month 12. Adverse events were documented for $54 \%$ patients. Few patients had treatment-associated adverse events (7\%). Acute severe visual acuity decrease occurred in two eyes (1\%), one of which had visual acuity that returned to baseline by the next follow-up visit.

Conclusions This study provides additional evidence that over 12 months, verteporfin is generally well tolerated and maintains or improves visual acuity in over one-third of eyes containing occult-only CNV. Verteporfin also improved anatomical outcomes by reducing leakage from $\mathrm{CNV}$ in at least two-thirds of eyes.

Eye (2009) 23, 791-800; doi:10.1038/eye.2008.158; published online 27 June 2008

Keywords: age-related macular degeneration; occult-only lesions; photodynamic therapy; verteporfin

\section{Introduction}

Age-related macular degeneration (AMD) is the most frequent cause of severe vision loss in the Western world in individuals older than 50 years. ${ }^{1-4}$ Occult choroidal neovascularization (CNV) is probably the most frequent type of CNV seen in eyes with AMD. Although no formal studies are available on the prevalence of lesion subtypes, it is estimated that patients with occult, with no classic lesion compositions, represent $40-80 \%$ of all cases of subfoveal neovascular AMD., ${ }^{5,6}$ Studies of the natural history of occult with no classic CNV indicate that it typically has a more benign prognosis than classic CNV. ${ }^{7-9}$ However, data from randomized, controlled trials suggest that a significant proportion of eyes with occult, with no classic $\mathrm{CNV}$, that have already lost vision will subsequently have severe decreases in visual acuity. ${ }^{10}$ In one study, $32 \%$ eyes with occult with no classic CNV had lesions that more than doubled in size during 9-12 months of follow-up, there was a median decrease in visual acuity of 12.5 letters, and classic CNV developed in $52 \%$ eyes. ${ }^{11}$ Furthermore, a recent meta-analysis showed that $70 \%$ eyes with occult with no classic CNV lost $\geqslant 10$ letters of visual acuity and $47 \%$ lost $\geqslant 30$ letters
${ }^{1}$ Departement d'Ophtalmologie, Hôpital Intercommunal de Créteil, Créteil Cedex, France

${ }^{2}$ St Paul's Clinical Eye Research Centre, Royal Liverpool \& Broadgreen University, Liverpool, UK

${ }^{3}$ Klinik und Poliklinik für Augenheilkunde, Inselspital, University Bern, Bern, Switzerland

${ }^{4}$ Novartis Pharma AG, WSJ-210.10.12, Basel, Switzerland

Correspondence: G Soubrane, Department of Ophthalmology, University-Paris XII-Créteil, 40 Avenue de Verdun, Créteil, France 94010, France

Tel: + 3314517 5222;

Fax: + 33145175227.

E-mail: gisele.soubrane@ chicreteil.fr

Received: 19 September 2007

Accepted in revised form: 15 April 2008

Published online: 27 June 2008

Results were presented at the Macula Society, 2006 
at 2-3 years. ${ }^{10}$ In addition, classic $\mathrm{CNV}$ developed at 1 year in $46 \%$ eyes.

Verteporfin (Visudyne ${ }^{\circledR}$; Novartis Pharma AG, Basel, Switzerland) is a light-activated agent used in photodynamic therapy that has been proven to safely reduce the risk of moderate and severe vision loss (loss of $\geqslant 15$ and $\geqslant 30$ letters of visual acuity, respectively) in a wide variety of eyes with subfoveal CNV due to AMD. ${ }^{12-14}$ In the Treatment of AMD with Photodynamic Therapy (TAP) investigation, verteporfin therapy was shown to significantly reduce the risk of moderate and severe vision loss in eyes with predominantly classic lesions (lesions composed of $\geqslant 50 \%$ classic CNV). ${ }^{12}$ The AMD arm of the Verteporfin in Photodynamic Therapy trial (VIP AMD trial) showed that verteporfin-treated eyes with subfoveal occult with no classic $\mathrm{CNV}$ were significantly more likely to lose $<15$ letters of visual acuity than eyes receiving placebo. ${ }^{13}$ After 24 months of treatment and follow-up, significantly more verteporfintreated eyes avoided at least moderate vision loss (45\% of 166 eyes), compared with placebo recipients (32\% of 92 eyes). Subgroup analysis showed that the greatest benefit was observed in the subgroup of eyes with either smaller lesions ( $\leqslant 4$ macular photocoagulation study disc areas (DAs)) or lower visual acuity ( $<65$ letters), in which a significantly larger percentage of verteporfin-treated eyes (51\%) lost $<15$ letters of visual acuity through 24 months, compared with placebo $(25 \% ; P<0.001){ }^{13}$

The Photodynamic Therapy in Occult-Only Lesions (POOL) study was conducted in European countries to evaluate the effect of verteporfin therapy on visual outcome over a 12-month period in subjects initially presenting with occult with no classic subfoveal CNV secondary to AMD.

On 26 April 2007, the Committee for Medicinal Products for Human Use (CHMP) of the European Medicines Agency recommended that the indication for verteporfin in the treatment of occult subfoveal $\mathrm{CNV}$ secondary to AMD be removed from the drug's labeling in Europe. However, the results presented in the POOL study are relevant to treating clinicians, because efficacy is often observed in these patients.

\section{Materials and methods}

\section{Study design and conduct}

The POOL study was a non-controlled, open-label, multicentre, 12-month phase IV study conducted from September 2003 to June 2005 at 24 centres (Appendix) in 12 European countries where verteporfin therapy is approved for the treatment of occult lesions. The study was designed and reported in accordance with the guidelines for Good Clinical Practice, as described by the
International Conference on Harmonization of Technical Requirements for Registration of Pharmaceuticals for Human Use (ICH), the ethical principles of the Declaration of Helsinki, and applicable local rules governing medicinal products in the European Community. The study protocol, the patient informed consent, and additional patient literature were reviewed and approved by Institutional Review Boards and Ethics Committees at each study centre before study initiation. All patients gave written informed consent to participate in the study.

\section{Patients}

Patients were enrolled based on the investigator's assessment of eligibility and interpretation of baseline fluorescein angiograms. Adult patients ( $\geqslant 50$ years) with subfoveal occult with no classic CNV due to AMD were enrolled in the study if they had presumed recent disease progression in the study eye. The area of the occult CNV had to occupy $\geqslant 50 \%$ of the entire lesion area. Only one eye was treated in each patient. If both eyes were eligible for treatment, the patient and investigator jointly decided which one was to be treated as the study eye. Recent disease progression was defined as blood associated with the lesion at baseline or loss of $\geqslant 6$ letters of visual acuity (Early Treatment of Diabetic Retinopathy study (ETDRS) equivalent) in the previous 3 months or at least a $10 \%$ increase in the greatest linear dimension (GLD) of the entire lesion on fluorescein angiography in the previous 3 months. In addition, eyes were required to have a baseline visual acuity letter score of $\geqslant 34$ (approximate Snellen equivalent 20/200), and a lesion GLD not exceeding $5400 \mu \mathrm{m}$ (diameter of a 9 DA circle).

\section{Treatment and follow-up}

Patients were treated at the baseline visit with a $10 \mathrm{~min}$ intravenous infusion of verteporfin $\left(6 \mathrm{mg} / \mathrm{m}^{2}\right)$, with activating light applied to the study eye $15 \mathrm{~min}$ after the start of the infusion at a wavelength of $689 \mathrm{~nm}$ and a light dose of $50 \mathrm{~J} / \mathrm{cm}^{2}\left(600 \mathrm{~mW} / \mathrm{cm}^{2}\right.$ for $\left.83 \mathrm{~s}\right)$. Additional verteporfin treatments were administered at months 3, 6, and 9 if angiography showed evidence of fluorescein leakage from CNV. No adjunctive treatments for AMD were permitted during the study. Patients were followed up at intervals of 3 months through month 12 (no treatment was administered at the month 12 visit).

\section{Visual acuity, angiographic, and safety assessments}

Eyes were assessed at baseline and the month 3, 6, 9, and 12 follow-up visits by ophthalmic examination, measurement of ETDRS visual acuity letter score, colour 
fundus photography, and fluorescein angiography. Study investigators assessed angiograms at baseline and all study visits to determine leakage from CNV. Fluorescein angiograms and colour fundus photographs from the baseline visit were also evaluated by a central photograph reading centre and were used to determine baseline lesion criteria for the subgroup analyses. Photograph reading centre evaluation of subsequent angiograms was only required if a serious ocular adverse event occurred. The primary outcome variable was the mean change from baseline to month 12 in the bestcorrected visual acuity score. Secondary outcome variables included the percentages of eyes with an improvement in visual acuity from a baseline of $\geqslant 5$ letters, decreases of $<5,<15$, or $<30$ letters, or a final visual acuity letter score of $<34$ (approximate Snellen equivalent 20/200). Angiographic assessments included the investigator's assessment of the percentage of eyes with fluorescein leakage at each 3-monthly follow-up and the percentage that developed a classic component in the study eye. Safety was assessed by evaluating adverse events, concomitant medications, ophthalmic examinations, and monitoring vital signs throughout the study.

\section{Statistical analysis}

The primary efficacy analyses were conducted within the intent-to-treat (ITT) population, which included all enrolled patients who received study medication, with the last observation carried forward in place of missing values. Safety analyses were conducted in all patients who received any treatment and performed at least one safety assessment after treatment. Planned analyses were also conducted within three subgroups of eyes categorized according to lesion size and visual acuity at baseline ( $\leqslant 4$ DAs and visual acuity letter score $<65 ; \leqslant 4$ DAs and visual acuity letter score $\geqslant 65$; and $>4$ DAs and visual acuity letter score $<65$ ), where a visual acuity letter score of 65 had an approximate Snellen equivalent of 20/50. A fourth unplanned subgroup analysis (lesion size $>4$ DAs and visual acuity letter score $\geqslant 65$ ) was subsequently performed.

No formal statistical testing was performed. For primary and secondary efficacy variables, summary statistics and frequency tables were provided for each follow-up visit. Safety was evaluated by tabulating reports of ocular and non-ocular adverse events.

\section{Statement of ethics}

We certify that all applicable institutional and governmental regulations concerning the ethical use of human volunteers were followed during this research.

\section{Results}

\section{Patient disposition and baseline characteristics}

A total of 202 patients were enrolled and received treatment with verteporfin therapy (Supplementary Figure 1). Eighteen patients $(8.9 \%)$ discontinued from the study, most frequently because of withdrawal of consent (7 patients, 3.5\%). Four patients $(2.0 \%)$ discontinued because of adverse events (see the section Safety). All 202 patients were included in the ITT and safety populations. Baseline characteristics of these patients are summarized in Table 1. All patients were Caucasian, two-thirds were women, and $58 \%$ were $>75$ years of age. According to the photograph reading centre evaluation of baseline angiograms, which could differ from the study investigator's baseline assessment of eligibility, most lesions were subfoveal or probably subfoveal $(85 \%)$ and the majority met the entry requirements of $\geqslant 50 \%$ occult CNV $(80 \%)$ and no classic CNV (84\%) (Table 1). There were seven cases of retinal choroidal anastomosis, as assessed by the reading centre.

\section{Study treatments}

All patients received verteporfin treatment at baseline in their study eye. Treatment was administered at subsequent visits only if there was evidence of fluorescein leakage, resulting in a progressive decrease in the number of eyes treated from $140(69.3 \%)$ at month 3 to $100(49.5 \%)$ at month 6 and $72(35.6 \%)$ at month 9. During the study, patients received a mean of 2.5 verteporfin treatments.

\section{Visual acuity outcomes}

At month 12, the mean change in visual acuity from baseline (the primary outcome variable) was -11.9 letters (Figure 1). Mean visual acuity scores decreased gradually in the course of the follow-up visits. At month 12, 164 eyes $(82.4 \%)$ had lost $<30$ letters of visual acuity, 123 eyes $(61.8 \%)$ had lost $<15$ letters, 78 eyes $(39.2 \%)$ had maintained or gained visual acuity by having lost $<5$ letters, $31(15.6 \%)$ had at least a 5-letter increase, and 7 eyes $(3.5 \%)$ had at least a 15-letter improvement. Fiftyfour eyes $(27.1 \%)$ had visual acuity letter scores of $<34$ (approximate Snellen equivalent 20/200) at month 12. The distribution of changes from baseline in visual acuity at month 12 is shown in Figure 2.

Subgroup analyses showed no clear differences in mean change in visual acuity between eyes with differing baseline visual acuities and lesion sizes. Mean changes in visual acuity letter scores at month 12 were within approximately two letters of the value in the total study population in all four subgroups (Table 2), with absolute 
Table 1 Baseline demographic and clinical characteristics (intent-to-treat population)

\begin{tabular}{|c|c|}
\hline Characteristics & Patients $(\mathrm{N}=202)$ \\
\hline \multicolumn{2}{|l|}{ Gender, $n(\%)$} \\
\hline Men & $68(33.7)$ \\
\hline Women & $134(66.3)$ \\
\hline \multicolumn{2}{|l|}{ Race, $n(\%)$} \\
\hline Caucasian & $202(100)$ \\
\hline \multicolumn{2}{|l|}{ Age, years } \\
\hline Mean (SD) & $76.4(7.32)$ \\
\hline Range & $52.1-92.2$ \\
\hline \multicolumn{2}{|l|}{ Age distribution (years), $n(\%)$} \\
\hline$<55$ & $1(0.5)$ \\
\hline $55-64$ & $12(5.9)$ \\
\hline $65-74$ & $72(35.6)$ \\
\hline $75-84$ & 96 (47.5) \\
\hline$\geqslant 85$ & $21(10.4)$ \\
\hline \multicolumn{2}{|l|}{ Evidence of $C N V, n(\%)$} \\
\hline Yes & 185 (91.6) \\
\hline No & $11(5.4)$ \\
\hline Questionable & $3(1.5)$ \\
\hline Cannot grade & $3(1.5)$ \\
\hline \multicolumn{2}{|l|}{ CNV location, $n(\%)$} \\
\hline Subfoveal & $164(81.2)$ \\
\hline Probably subfoveal & $8(4.0)$ \\
\hline Not subfoveal & $16(7.9)$ \\
\hline Cannot grade & $14(6.9)$ \\
\hline \multicolumn{2}{|c|}{ Occult $C N V \geqslant 50 \%$ of lesions, $n(\%)$} \\
\hline Yes & $161(79.7)$ \\
\hline No & $30(14.9)$ \\
\hline Questionable & $8(4.0)$ \\
\hline Cannot grade & $3(1.5)$ \\
\hline \multicolumn{2}{|l|}{ Classic CNV, $n(\%)$} \\
\hline Yes & $22(10.9)$ \\
\hline No & $170(84.2)$ \\
\hline Questionable & $8(4.0)$ \\
\hline Cannot grade & $2(1.0)$ \\
\hline \multicolumn{2}{|l|}{ Blood } \\
\hline Yes & $40(19.8)$ \\
\hline No & $160(79.2)$ \\
\hline Cannot grade & $2(1.0)$ \\
\hline Area of lesion, $\mathrm{mm}^{2}$ & $(N=187)^{\mathrm{a}}$ \\
\hline Mean (SD) & $8.0(5.44)$ \\
\hline Range & $0.18-37.94$ \\
\hline Greatest linear dimension, $\mu m$ & $(N=187)^{\mathrm{a}}$ \\
\hline Mean (SD) & $3558.4(1260.12)$ \\
\hline Range & $430-7779$ \\
\hline
\end{tabular}

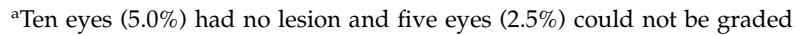
Data on lesion characteristics are from reading centre grading.

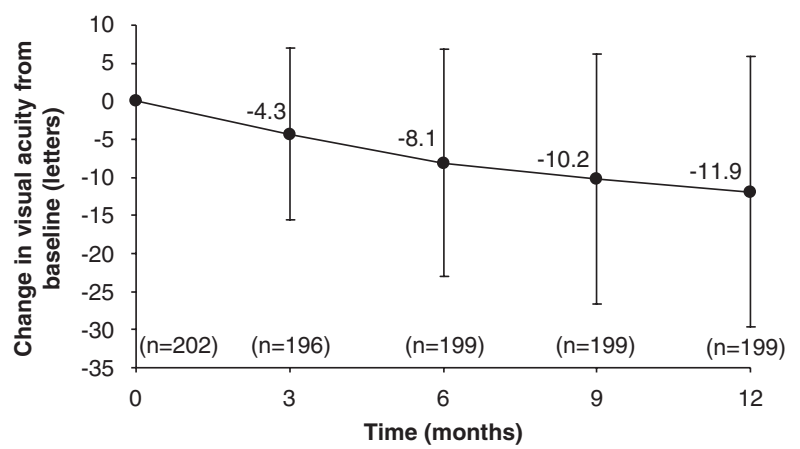

Figure 1 Mean change ( $\pm S D$ ) in visual acuity from baseline.

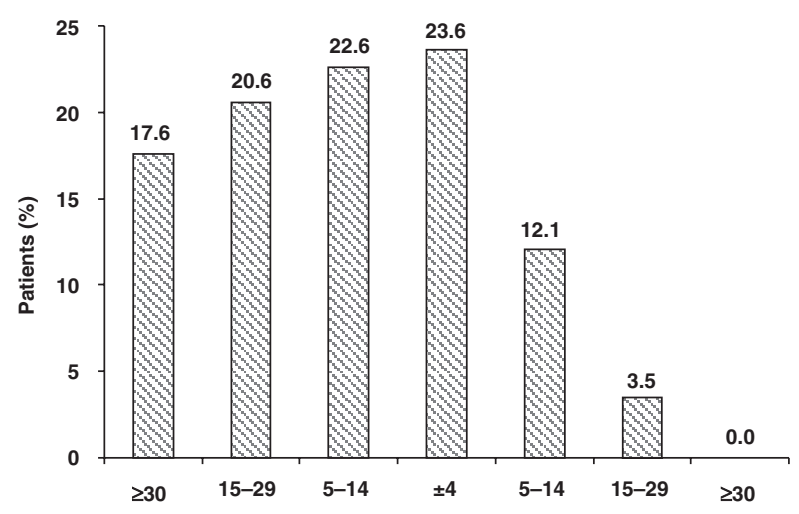

Figure 2 Frequency distribution of change from baseline in visual acuity letter score at month 12 .

$t$-score values lower than 1 for all pair-wise subgroup differences, indicating corresponding $P$-values of $>0.3$. Excluding 32 patients with classic $\mathrm{CNV}$ or questionable status regarding classic $\mathrm{CNV}$ from the analysis had little effect on the mean change in visual acuity letter scores at month 12, compared with the total study population $(-11.9 \pm 17.7$ letters (total) $v s-11.2 \pm 18.2$ letters).

\section{Angiographic outcomes}

Evidence of fluorescein leakage from CNV was observed in a decreasing proportion of eyes at each subsequent visit over the 12-month period, with leakage observed in 75.5\% eyes at month 3 and $25.1 \%$ at month 12 .

Development of classic CNV (based on the investigator's assessment at baseline and during follow-up) was infrequent, occurring in $<15 \%$ eyes at all study visits (Supplementary Table 1).

\section{Safety}

Adverse events were reported in 109 patients (54\%); most (73\%) were of mild or moderate intensity with only 29 
Table 2 Change from baseline in visual acuity letter score in all patients and in the subgroups of patients divided according to baseline lesion size and visual acuity

\begin{tabular}{|c|c|c|c|c|c|}
\hline & \multirow[t]{2}{*}{ All patients } & \multicolumn{4}{|c|}{ Subgroup } \\
\hline & & $\begin{array}{l}\text { Lower VA and } \\
\text { smaller lesions }{ }^{\mathrm{a}}\end{array}$ & $\begin{array}{l}\text { Higher VA and } \\
\text { smaller lesions }\end{array}$ & $\begin{array}{l}\text { Lower VA and } \\
\text { larger lesions }{ }^{\mathrm{c}}\end{array}$ & $\begin{array}{c}\text { Higher VA } \\
\text { and larger lesions }\end{array}$ \\
\hline Patients, $n$ & 202 & 92 & 49 & 43 & 13 \\
\hline Mean (SD) baseline VA, letters & $58.1(11.64)$ & $51.7(8.84)$ & $71.1(4.54)$ & $52.9(7.99)$ & $72.1(5.59)$ \\
\hline \multicolumn{6}{|c|}{ Mean (SD) VA change from baseline, letters } \\
\hline Month 3 & $-4.3(11.34)$ & $-4.7(11.58)$ & $-4.6(10.33)$ & $-2.8(11.82)$ & $-7.9(10.97)$ \\
\hline Month 6 & $-8.1(14.88)$ & $-8.3(14.44)$ & $-7.9(13.49)$ & $-7.6(16.95)$ & $-9.7(15.55)$ \\
\hline Month 9 & $-10.2(16.44)$ & $-10.0(16.15)$ & $-10.7(16.99)$ & $-10.4(16.90)$ & $-10.3(14.72)$ \\
\hline Month $12^{\mathrm{e}}$ & $-11.9(17.73)$ & $-12.0(16.99)$ & $-13.4(18.59)$ & $-9.8(17.87)$ & $-14.1(16.54)$ \\
\hline
\end{tabular}

VA, visual acuity.

${ }^{\mathrm{a} V A}<65$ letters, lesion $\leqslant 4$ DA.

${ }^{\text {bVA }} \geqslant 65$ letters, lesion $\leqslant 4$ DA.

${ }^{\mathrm{c} V A}<65$ letters, lesion $>4$ DA.

${ }^{\mathrm{d}} \mathrm{VA} \geqslant 65$ letters, lesion $>4$ DA (this category was an unplanned analysis).

${ }^{\mathrm{e}}$ Absolute $t$-score values $<1$ for all pair-wise subgroup differences, indicating corresponding $P$-values of $>0.3$.

patients (14\%) having severe adverse events (Table 3). The most frequent adverse events were abnormal vision (8.9\%) and infection (5.4\%; the term 'infection' refers to the body as a whole, and includes chest infection, cold symptoms, common cold, and toe infection), with all other adverse events occurring in $<5 \%$ of patients. Fourteen patients (6.9\%) had adverse events that were considered by the investigator to be associated with treatment. Ocular adverse events occurred in 43 patients (21.3\%) and were mostly of mild (24 patients) or moderate (10 patients) intensity. The most frequent ocular adverse events were abnormal vision (18 patients, $8.9 \%)$, retinal disorder (6 patients, $3.0 \%$ ), conjunctivitis (4 patients, 2.0\%), and eye disorder (4 patients, 2.0\%).

Thirty-one patients had serious adverse events (three of which were associated with treatment) and there were three deaths (none associated with treatment). The three deaths were those of one 86-year-old patient (coronary artery atheroma 4 weeks after completing the third visit), one 73-year-old patient (myocardial infarction 8 weeks after completing the first visit), and one 84-year-old patient (bowel cancer 12 weeks after completing the first visit). The serious adverse events judged to be associated with treatment included two cases of protocol-defined acute severe visual acuity decrease (loss of $\geqslant 20$ letters of visual acuity within 7 days of treatment). The first patient had a baseline visual acuity letter score of 61 and experienced an acute severe decrease of 22 letters from baseline on day 5 after the first treatment with verteporfin therapy. The patient made a complete recovery (visual acuity letter score 75 ) by the month 3 visit and had stable vision through month 12 (visual acuity letter score 67). A second patient experienced a probable acute severe visual acuity decrease after the first treatment. When he attended his month 3 visit, he reported experiencing acute severe visual acuity loss on the sixth day after initial treatment. The patient had not reported this vision loss to his physician until the next scheduled visit, so no visual acuity assessment was performed within 7 days that would confirm his vision loss as a protocol-defined severe visual acuity decrease event. His baseline visual acuity letter score was 70, whereas his visual acuity letter score at month 3 was 43, reflecting a loss of 27 letters; his vision remained stable for the remainder of the study through the month 12 visit (final visual acuity letter score 40). Another serious treatment-associated adverse event was an eye haemorrhage on day 10 after the second verteporfin treatment, resulting in the patient's discontinuation from the study. An ultrasound examination showed vitreous haemorrhage and subretinal haemorrhage temporalinferior to the fovea. No retinal detachment was observed. A vitrectomy was performed and the patient was classified as having recovered with sequelae. Three patients discontinued because of adverse events that were not related to the study treatment (gastrointestinal carcinoma, dementia, and depression).

\section{Discussion}

This study of eyes with occult with no classic CNV secondary to AMD with presumed recent disease progression showed that $61.8 \%$ of verteporfin-treated eyes lost $<15$ letters of visual acuity during 12 months. Additionally, $39.2 \%$ eyes lost $<5$ letters, $15.6 \%$ had at least minimal improvement ( $\geqslant 5$-letter increase), and $3.5 \%$ had at least a $15-$ letter improvement. These visual acuity outcomes compare favourably with results from 
Table 3 Adverse events by coding symbols for a thesaurus of adverse reaction terms (COSTART); preferred terms occurred in at least $2.5 \%$ of the 202 patients studied

\begin{tabular}{|c|c|c|c|c|}
\hline & \multicolumn{4}{|c|}{ Patients with at least one adverse event } \\
\hline & $\begin{array}{c}\text { All intensities } \\
\mathrm{n}(\%)\end{array}$ & $\begin{array}{c}\text { Mild }^{\mathrm{a}} \\
\mathrm{n}\end{array}$ & $\begin{array}{c}\text { Moderate }^{\mathrm{b}} \\
\mathrm{n}\end{array}$ & $\begin{array}{c}\text { Severe }^{\mathrm{c}} \\
\mathrm{n}\end{array}$ \\
\hline Any adverse event & $109(54.0)$ & 43 & 37 & 29 \\
\hline \multicolumn{5}{|l|}{ Body as a whole } \\
\hline Back pain & $9(4.5)$ & 5 & 3 & 1 \\
\hline Flu syndrome & $5(2.5)$ & 3 & 2 & 0 \\
\hline Headache & $8(4.0)$ & 5 & 3 & 0 \\
\hline Infection & $11(5.4)$ & 8 & 3 & 0 \\
\hline Intentional injury & $8(4.0)$ & 1 & 6 & 1 \\
\hline Pain & $6(3.0)$ & 3 & 3 & 0 \\
\hline Injection-site reaction & $2(1.0)$ & 2 & 0 & 0 \\
\hline \multicolumn{5}{|l|}{ Digestive system } \\
\hline $\begin{array}{l}\text { Gastrointestinal } \\
\text { disorder }\end{array}$ & $5(2.5)$ & 1 & 4 & 0 \\
\hline Nausea & $5(2.5)$ & 3 & 2 & 0 \\
\hline \multicolumn{5}{|l|}{ Musculoskeletal } \\
\hline Bone disorder & $5(2.5)$ & 1 & 2 & 2 \\
\hline \multicolumn{5}{|l|}{ Treatment-site ocular } \\
\hline Abnormal vision $^{\mathrm{d}}$ & $18(8.9)$ & 9 & 4 & 5 \\
\hline Retinal disorder & $6(3.0)$ & 1 & 3 & 2 \\
\hline Conjunctivitis & $4(2.0)$ & 4 & 0 & 0 \\
\hline Retinal haemorrhage & $3(1.5)$ & 1 & 0 & 2 \\
\hline Visual field defect & $3(1.5)$ & 2 & 1 & 0 \\
\hline Eye disorder ${ }^{f}$ & $4(2.0)$ & 3 & 1 & 0 \\
\hline Chromatopsia & $2(1.0)$ & 2 & 0 & 0 \\
\hline Lacrimation disorder & $2(1.0)$ & 2 & 0 & 0 \\
\hline Cataract specified & $1(0.5)$ & 1 & 0 & 0 \\
\hline Dry eyes & $1(0.5)$ & 1 & 0 & 0 \\
\hline Eye haemorrhage & $1(0.5)$ & 0 & 0 & 1 \\
\hline Eye pain & $1(0.5)$ & 1 & 0 & 0 \\
\hline Eyelid disorder & $1(0.5)$ & 1 & 0 & 0 \\
\hline Face oedema & $1(0.5)$ & 1 & 0 & 0 \\
\hline Glaucoma & $1(0.5)$ & 1 & 0 & 0 \\
\hline Retinal detachment & $1(0.5)$ & 0 & 1 & 0 \\
\hline Vitreous disorder & $1(0.5)$ & 0 & 1 & 0 \\
\hline
\end{tabular}

${ }^{\mathrm{a}}$ Events without impact on daily activities.

${ }^{\mathrm{b}}$ Events interfering with daily activities.

'Events rendering daily activities impossible.

${ }^{\mathrm{d}}$ Includes the other one of the two patients with acute severe visual acuity decrease. Adverse events are listed if they occurred in at least $2.5 \%$ patients, with the exception of events of special interest (injection-site reactions) and treatment-site ocular adverse events, which are listed in detail.

'Includes chorioretinal anastomosis (one case), tear in retinal pigment epithelium (RPE; three cases), rip in RPE (two cases) (includes one of the two patients with acute severe visual acuity decrease).

${ }^{\mathrm{f}}$ Worsening occult $\mathrm{CNV}$ or AMD, possible tear at site of lesion.

the VIP AMD trial, in which $49 \%$ of 166 verteporfintreated eyes with occult with no classic CNV lost $<15$ letters of visual acuity at month $12 .{ }^{13}$ The lower mean changes in visual acuity between baseline and month 12 in the present study (-11.9 letters), compared with the VIP AMD trial (-15.6 letters), may reflect differences in baseline visual acuity letter scores (58 in the present study and 66 in the VIP AMD trial).

In the VIP AMD trial, the greatest visual acuity benefits were seen in eyes with occult with no classic CNV and either smaller lesions or lower levels of visual acuity at baseline. Visual acuity outcomes in the current study were similar across all subgroups of eyes with smaller or larger lesions and lower or higher levels of visual acuity at baseline. The planned subgroups together $(\leqslant 4$ DAs and visual acuity letter score $<65 ; \leqslant 4$ DAs and visual acuity letter score $\geqslant 65$; and $>4$ DAs and visual acuity letter score $<65$ ) represent the category (either smaller lesions or lower levels of visual acuity) that had the greatest visual acuity benefit in the VIP AMD trial. The mean visual acuity change from baseline for the three planned subgroups from the current study at month 12 $(-12.0,-13.4$, and -9.8 letters, respectively) was similar to that for the VIP AMD trial subgroup of smaller lesions or lower levels of visual acuity ( -13.1 letters). ${ }^{13}$ The mean visual acuity change from baseline for the unplanned subgroup in the current study ( $>4$ DAs and visual acuity letter score $\geqslant 65)$ was also similar $(-14.1$ letters) to the planned subgroups, as well as to the VIP AMD subgroup that showed the greatest benefit. However, results are not directly comparable, because differences in outcomes between the VIP AMD trial and the present study may have been due to differences in lesion characteristics, treatment criteria, and duration of experience with verteporfin therapy in each study. Nevertheless, the similar outcomes across the subgroups in the present study indicate that baseline lesion size and visual acuity may not be as strong an influence on treatment outcomes as had been shown in previous analyses.

A recent retrospective, observational study of 277 patients with occult-only or predominantly classic $\mathrm{CNV}$ secondary to AMD investigated whether a difference in visual outcomes was detectable after treatment of these lesion subtypes with verteporfin therapy. ${ }^{15}$ Patients with occult lesions lost an average of 8.7 letters (1.9 lines) from baseline over 12 months, compared with 10.0 letters (2 lines) in patients with predominantly classic lesions (difference of 1.3 letters). The mean letters lost at 12 months was not significantly different between the two groups $(P=0.411)$, and a minimal clinically important difference (set at 7.5 letters) was not detected..$^{15}$

Eyes receiving verteporfin in this study also had improvements in angiographic outcomes between baseline and 12 months. At baseline, fluorescein leakage was present in 100\% eyes according to the investigator's assessment and $91.6 \%$ eyes according to the reading centre. The percentage of eyes with evidence of 
fluorescein leakage from CNV (investigator assessments) decreased progressively at each follow-up visit, from $75.5 \%$ at month 3 to $25.1 \%$ at month 12 . The decreasing occurrence of leakage resulted in decreases in the number of eyes requiring verteporfin at each visit, from $69.3 \%$ at month 3 to $35.6 \%$ at month 9. During the study, patients received a mean of 2.5 verteporfin treatments in the study eye, which was lower than the mean of 3.1 treatments administered to eyes with occult with no classic CNV during the first 12 months of the VIP AMD trial.

Safety results in this study were consistent with the VIP AMD trial and TAP investigation, and there were no new safety concerns. Verteporfin was generally well tolerated and associated with a low incidence of adverse events. Acute severe visual acuity decreases were uncommon, occurring in two patients $(1.0 \%)$, one of whose vision recovered at the next 3-monthly visit. This incidence is lower than that reported in the 2-year pooled data from the TAP investigation and VIP AMD trial $(2.2 \%){ }^{16}$

Since the completion of this study, excellent results have been reported from two large-scale, randomized, controlled phase III trials-MARINA (minimally classic or occult-only) and ANCHOR (predominantly classic) - evaluating the antivascular endothelial growth factor (VEGF) antibody ranibizumab (Lucentis ${ }^{\circledR}$; Genentech, San Francisco, CA, USA). ${ }^{17,18}$ One-year data showed that patients receiving monthly intravitreal injections of ranibizumab $(0.5 \mathrm{mg})$ had a mean increase in visual acuity of 7.2-11.3 letters, whereas approximately $95 \%$ patients lost $<15$ letters. ${ }^{17,18}$ Benefits in visual acuity were maintained at 24 months, and ranibizumab also appeared to be generally safe and well tolerated. ${ }^{18,19}$ Following the approval of ranibizumab, there has been a revolution in the treatment of neovascular AMD. ${ }^{20}$ There have also been reports of the full-length, monoclonal anti-VEGF antibody bevacizumab (Avastin ${ }^{\mathbb{}}$;

Genentech), which is approved for certain solid tumours (ie, metastatic colorectal cancer, non-small-cell lung cancer, breast cancer), administered as intravitreal injection in patients with neovascular AMD. ${ }^{21-28}$ Findings from these small-scale, short-term, noncontrolled, non-randomized studies or case series have shown improvements in visual acuity of 3.1-7.4 letters from baseline over 1-12 months follow-up, as well as anatomical benefits, following bevacizumab. ${ }^{21-25}$ Although bevacizumab was generally well tolerated, adverse events included endophthalmitis, retinal pigment epithelial tears, and submacular haemorrhage. ${ }^{21,26,28}$ The long-term efficacy and safety of bevacizumab in neovascular AMD have yet to be elucidated in large-scale, randomized, controlled trials.
Before the availability of anti-VEGF agents, there were reports of improved visual acuity from baseline in patients with neovascular AMD following treatment with verteporfin combined with anti-inflammatory steroids such as intravitreal triamcinolone acetonide. ${ }^{29,30}$ There is now increasing interest in using verteporfin in combination with anti-VEGF therapies with or without concomitant anti-inflammatory agents. ${ }^{31-35}$ Same-day administration of verteporfin combined with ranibizumab $(0.5 \mathrm{mg})$ in an open-label, phase II study of 32 patients with occult $(n=19)$ or predominantly classic $(n=13)$ lesions was shown to be safe and improve visual acuity and anatomical outcomes over 9 months. ${ }^{36,37}$ The hypothesis that the combination of therapies with different mechanisms of action, that is, verteporfin and ranibizumab, may lead to synergistic effects and improved clinical outcomes are being further investigated in the large-scale phase IIIb SUMMIT program. This comprises two prospective, randomized, controlled studies - DENALI (US and Canada) and MONT BLANC (Europe). ${ }^{38}$

The limitations of the present study should be noted. In particular, this was an open-label study with no comparator group, thereby limiting the conclusions that can be drawn. Additionally, the study included a number of patients who did not meet the eligibility criteria as determined by the photograph reading centre, including $7.9 \%$ whose CNV was not subfoveal, $14.1 \%$ who did not have occult $\mathrm{CNV}, 5.0 \%$ who had no lesion, $10.9 \%$ who had classic CNV present, and $5.4 \%$ who had no CNV. However, these patients were considered to meet the eligibility criteria by the enrolling investigator, and the overall study population therefore reflects the patients likely to be identified as having 'occult with no classic $\mathrm{CNV}^{\prime}$ in clinical practice. The similar visual acuity findings in the total study population and in those with no classic $\mathrm{CNV}$ indicate that the inclusion of 32 patients with classic $\mathrm{CNV}$ or questionable status regarding classic $\mathrm{CNV}$ appears to not have an impact on vision outcomes.

In conclusion, the findings from this study provide additional data on verteporfin therapy in patients with occult CNV lesions and are consistent with the outcomes of the VIP AMD trial. Verteporfin therapy appeared to be safe and well tolerated, and no new safety concerns were raised in this study over 12 months. Visual acuity was maintained or improved in over one-third of eyes, and two-thirds of eyes showed reduced leakage from CNV.

\section{Acknowledgements}

Dr Neil M Bressler provided extensive editorial review of this manuscript. Additional comments were obtained from research and marketing employees of Novartis Pharma AG and QLT Inc. This study was sponsored by 
Novartis Pharma AG (Basel, Switzerland) and QLT Inc. (Vancouver, British Columbia, Canada).

\section{Financial disclosures}

As on 1 September 2006, Dr Bressler's employer, the Johns Hopkins University, but not Dr Bressler, receives funding from Genentech, Notal Vision Inc., Novartis, (osi) Eyetech, Carl Zeiss Meditec, Othera, QLT Inc., TargeGen, Acucela, and Regeneron for sponsored projects by the Department of Ophthalmology for effort of Dr Bressler. Dr Bressler receives salary support for these sponsored projects; the terms of these projects are negotiated and administered by the Office of Research Administration. Under the School's policy, support for the costs of research, administered by the institution, does not constitute a conflict of interest.

The following authors have indicated that they are being or have been paid as consultants to QLT Inc. or Novartis Pharma AG or both (which may also include travel expenses at congresses or participation in a speakers' bureau or advisory board meeting):

Gisèle Soubrane, Simon Harding, and Sebastian Wolf have received financial support from Novartis Pharma AG for travel expenses and contributions to conferences and advisory boards. They hold no equity in QLT Inc. or Novartis Pharma AG.

Simon Harding and Sebastian Wolf have received institutional support for commercially sponsored studies.

\section{References}

1 Buch H, Vinding T, La Cour M, Jensen GB, Prause JU, Nielsen NV. Prevalence and causes of visual impairment and blindness among 9980 Scandinavian adults: the Copenhagen City Eye Study. Ophthalmology 2004; 111: 53-61.

2 Congdon N, O'Colmain B, Klaver CC, Klein R, Muñoz B, Friedman DS et al. Causes and prevalence of visual impairment among adults in the United States. Arch Ophthalmol 2004; 122: 477-485.

3 Dimitrov PN, Mukesh BN, McCarty CA, Taylor HR. Fiveyear incidence of bilateral cause-specific visual impairment in the Melbourne Visual Impairment Project. Invest Ophthalmol Vis Sci 2003; 44: 5075-5081.

4 Foran S, Wang JJ, Mitchell P. Causes of visual impairment in two older population cross-sections: the Blue Mountains Eye Study. Ophthalmic Epidemiol 2003; 10: 215-225.

5 Freund KB, Yannuzzi LA, Sorenson JA. Age-related macular degeneration and choroidal neovascularization. Am J Ophthalmol 1993; 115: 786-791.

6 Bressler NM, Bressler SB, Gragoudas ES. Clinical characteristics of choroidal neovascular membranes. Arch Ophthalmol 1987; 105: 209-213.

7 Bressler NM, Frost LA, Bressler SB, Murphy RP, Fine SL. Natural course of poorly defined choroidal neovascularization associated with macular degeneration. Arch Ophthalmol 1988; 106: 1537-1542.

8 Bressler NM, Maguire MG, Murphy PL, Alexander J, Margherio R, Schachat AP et al. Macular scatter ('grid') laser treatment of poorly demarcated subfoveal choroidal neovascularization in age-related macular degeneration. Results of a randomized pilot trial. Arch Ophthalmol 1996; 114: $1456-1464$

9 Macular Photocoagulation Study Group. Occult choroidal neovascularization. Influence on visual outcome in patients with age-related macular degeneration. Arch Ophthalmol 1996; 114: 400-412.

10 Polito A, Isola M, Lanzetta P, Gregori D, Bandello F. The natural history of occult choroidal neovascularisation associated with age-related macular degeneration. A systematic review. Ann Acad Med Singapore 2006; 35: 145-150.

11 Stevens TS, Bressler NM, Maguire MG, Bressler SB, Fine SL, Alexander $\mathrm{J}$ et al. Occult choroidal neovascularization in age-related macular degeneration. A natural history study. Arch Ophthalmol 1997; 115: 345-350.

12 Treatment of Age-Related Macular Degeneration with Photodynamic Therapy (TAP) Study Group. Photodynamic therapy of subfoveal choroidal neovascularization in age-related macular degeneration with verteporfin: two-year results of 2 randomized clinical trials-TAP Report 2. Arch Ophthalmol 2001; 119: 198-207.

13 Verteporfin In Photodynamic Therapy (VIP) Study Group. Verteporfin therapy of subfoveal choroidal neovascularization in age-related macular degeneration: two-year results of a randomized clinical trial including lesions with occult with no classic choroidal neovascularization-Verteporfin In Photodynamic Therapy Report 2. Am J Ophthalmol 2001; 131: 541-560.

14 Visudyne In Minimally Classic CNV (VIM) Study Group. Verteporfin therapy of subfoveal minimally classic choroidal neovascularization in age-related macular degeneration: 2-year results of a randomized clinical trial. Arch Ophthalmol 2005; 123: 448-457.

15 Potter MJ, Szabo SM, Li WW. Comparison of visual acuity outcomes in predominantly classic vs occult lesions in age-related macular degeneration treated with photodynamic therapy. Eye 2008; 22: 194-199.

16 Treatment of Age-Related Macular Degeneration with Photodynamic Therapy (TAP) and Verteporfin In Photodynamic Therapy (VIP) Study Groups. Acute severe visual acuity decrease after photodynamic therapy with verteporfin: case reports from randomized clinical trials-TAP and VIP Report No. 3. Am J Ophthalmol 2004; 137: 683-696.

17 Brown DM, Kaiser PK, Michels M, Soubrane G, Heier JS, Kim RY et al. Ranibizumab vs verteporfin for neovascular age-related macular degeneration. $N$ Engl J Med 2006; 355 1432-1444.

18 Rosenfeld PJ, Brown DM, Heier JS, Boyer DS, Kaiser PK, Chung CY et al. Ranibizumab for neovascular age-related macular degeneration. $N$ Engl J Med 2006; 355: 1419-1431.

19 Heier III JS, Chung C, Schneider S. Time course of visual acuity changes with ranibizumab (Lucentis ${ }^{\mathrm{TM}}$ ) in the 2-Year ANCHOR study of patients with neovascular age-related macular degeneration (AMD). Invest Ophthalmol Vis Sci 2007; 48: 2872.

20 Brown DM, Regillo CD. Anti-VEGF agents in the treatment of neovascular age-related macular degeneration: applying clinical trial results to the treatment of everyday patients. Am J Ophthalmol 2007; 144: 627-637.

21 Bashshur ZF, Haddad ZA, Schakal A, Jaafar RF, Saab M, Noureddin BN. Intravitreal Bevacizumab for treatment of 
neovascular age-related macular degeneration: a one-year prospective study. Am J Ophthalmol 2008; 145: 249-256.

22 Emerson MV, Lauer AK, Flaxel CJ, Wilson DJ, Francis PJ, Stout JT et al. Intravitreal bevacizumab (Avastin) treatment of neovascular age-related macular degeneration. Retina 2007; 27: 439-444.

23 Lazic R, Gabric N. Intravitreally administered bevacizumab (Avastin) in minimally classic and occult choroidal neovascularization secondary to age-related macular degeneration. Graefes Arch Clin Exp Ophthalmol 2007; 245: 68-73.

24 Algvere PV, Steén B, Seregard S, Kvanta A. A prospective study on intravitreal bevacizumab (Avastin) for neovascular age-related macular degeneration of different durations. Acta Ophthalmol Scand 2007 [e-pub ahead of print].

25 Pedersen R, Soliman W, Lund-Andersen H, Larsen M. Treatment of choroidal neovascularization using intravitreal bevacizumab. Acta Ophthalmol Scand 2007; 85: 526-533.

26 Avery RL, Pieramici DJ, Rabena MD, Castellarin AA, Nasir MA, Giust MJ. Intravitreal bevacizumab (Avastin) for neovascular age-related macular degeneration. Ophthalmology 2006; 113: 363-372.

27 Rich RM, Rosenfeld PJ, Puliafito CA, Dubovy SR, Davis JL, Flynn Jr HW et al. Short-term safety and efficacy of intravitreal bevacizumab (Avastin) for neovascular agerelated macular degeneration. Retina 2006; 26: 495-511.

28 Cleary CA, Jungkim S, Ravikumar K, Kelliher C, Acheson RW, Hickey-Dwyer M. Intravitreal bevacizumab in the treatment of neovascular age-related macular degeneration, 6- and 9-month results. Eye 2008; 22: 82-86.

29 Spaide RF, Sorenson J, Maranan L. Photodynamic therapy with verteporfin combined with intravitreal injection of triamcinolone acetonide for choroidal neovascularization. Ophthalmology 2005; 112: 301-304.

30 Augustin AJ, Schmidt-Erfurth U. Verteporfin therapy combined with intravitreal triamcinolone in all types of choroidal neovascularization due to age-related macular degeneration. Ophthalmology 2006; 113: 14-22.

31 Kiss CG, Wagner J, Simader C, Michels S, Schmidt-Erfurth U. Effect of photodynamic therapy (PDT) and ranibizumab on vascular anatomy and retinal function in neovascular agerelated macular degeneration. Invest Ophthalmol Vis Sci 2007; 48: 4544.

32 Lazic R, Gabric N. Verteporfin therapy and intravitreal bevacizumab combined and alone in choroidal neovascularization due to age-related macular degeneration. Ophthalmology 2007; 114: 1179-1185.

33 Costa RA, Jorge R, Calucci D, Melo Jr LA, Cardillo JA, Scott IU. Intravitreal bevacizumab (Avastin) in combination with verteporfin photodynamic therapy for choroidal neovascularization associated with age-related macular degeneration (IBeVe Study). Graefes Arch Clin Exp Ophthalmol 2007; 245: 1273-1280.

34 Romero RM, Monares G, De la Luz JC, Morales A, Padilla G, Niño-Pecina A et al. Randomized, double blind, controlled study with verteporfin photodynamic therapy and intravitreal triamcinolone (IVTA) vs Triple theraphy with verteporfin photodynamic therapy, intravitreal triamcinolone and intravitreal ranibizumab in patients with subfoveal choroidal neovascularization (CNV) secondary to age-related macular degeneration (AMD). Invest Ophthalmol Vis Sci 2007; 48: 72.

35 Augustin AJ, Puls S, Offermann I. Triple therapy for choroidal neovascularization due to age-related macular degeneration: verteporfin PDT, bevacizumab, and dexamethasone. Retina 2007; 27: 133-140.

36 Holz FG, PROTECT Study Group. Nine month safety and efficacy results from an open-label, multicenter, phase II study of same-day verteporfin and ranibizumab $0.5 \mathrm{mg}$ (PROTECT Study). Invest Ophthalmol Vis Sci 2007; 48: 4566.

37 Wolf S, PROTECT Study Group. Nine month exploratory endpoint results from an open-label, multicenter, phase II study of same-day verteporfin and ranibizumab $0.5 \mathrm{mg}$ (PROTECT Study), as measured using optical coherence tomography (OCT), fundus photography and fluorescein angiography (FA). Invest Ophthalmol Vis Sci 2007; 48: 2871

38 Slakter JS, DENALI Study Group. SUMMIT: combination therapy with verteporfin PDT and ranibizumab for subfoveal choroidal neovascularization due to AMD. Invest Ophthalmol Vis Sci 2007; 48: 1817.

\section{Appendix}

\section{Photodynamic Therapy in Occult-Only Lesions (POOL) study group clinical centres}

Allgemeines Krankenhaus (AKH), Klinik für

Augenheilkunde, Wien, Austria

KH der Barmherzigen Brüder, Linz, Austria

Department of Ophthalmology, Herlev Hospital,

Herlev, Denmark

Department of Ophthalmology, Kuopio University

Hospital, Kuopio, Finland

Departement d'Ophtalmologie, Hôpital

Intercommunal de Créteil, Créteil Cedex, France

Cabinet Ophtalmologie, 26, rue Crillon, Lyon, France

Klinikum Darmstadt, Abteilung Eberstadt

Augenklinik, Darmstadt, Germany

Klinikum der Universität, Augenabteilung,

Regensburg, Germany

Department of Ophthalmology, St-Franziskus-

Hospital, Münster, Germany

Universitätsklinikum Leipzig, Klinik und Poliklinik

für Augenheilkunde, Leipzig, Germany

Dipartimento di oftalmologia e scienze della visione,

Università di Milano, Milano, Italy

Department of Oto-Neuro-Ophthalmological Surgical

Sciences, Eye Clinic II, Firenze, Italy

Department of Ophthalmology and Eye Clinic of 2nd

Medical Faculty, Medical Academy in Warsaw,

Warszawa, Poland

Associação para Investigação Biomédica e Inovação em Luz e Imagen, Coimbra, Portugal

Ciutat Sanitaria i Universitaria de Bellvitge, Barcelona, Spain

Hospital Universitario 'La Paz', Oftalmología, Madrid, Spain

Instituto Tecnologico de Oftalmología, Hospital

Nuestra Señora de La Esperanza, Santiago de

Compostela, Spain 
Servicio de Oftalmologia, consultas externa, Hospital Universitario 'La Fe,' Valencia, Spain

Instituto Oftalmologico de Alicante (IOA), Alicante, Spain Universitetssjukhuset, Ögonkliniken, Linköping, Sweden Bern Photographic Reading Center, Klinik und

Poliklinik für Augenheilkunde, Inselspital, University

Bern, Switzerland
The Rotterdam Eye Hospital, Rotterdam, The Netherlands

St Paul's Clinical Eye Research Centre, Royal Liverpool \& Broadgreen University, Liverpool, UK

Wolverhampton and Midland Counties Eye Infirmary, West Midlands, UK

Retina Division, Moorfields Eye Hospital, London, UK

Supplementary Information accompanies the paper on Eye website (http://www.nature.com/eye) 